\title{
SOME PHYSICAL PROPERTIES OF PLATINUM-RHODIUM ALLOYS
}

\author{
By J. S. Acken ${ }^{1}$
}

\section{ABSTRACT}

In a continuation of the study at the Bureau of the metals of the platinum group, a series of platinum-rhodium alloys containing approximately 10, 20, 40, 60 , and 80 percent rhodium was prepared from pure platinum and pure rhodium. The melting point, hardness, density, electrical resistivity, temperature coefficient of resistance, and thermal electromotive force against platinum were determined for each alloy. The microstructure of each alloy appeared to be that of a solid solution. The particular qualifications of the alloys containing 20 to 40 percent of rhodium, for use as resistance furnace windings for service at high temperatures, are discussed.

CONTENTS

Introduction -----1

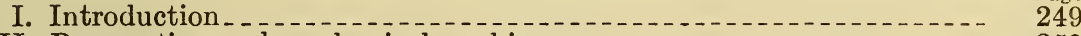

II. Preparation and mechanical working

III. Physical properties................ 252

1. Melting point

2. Hardness

3. Density _...

4. Electrical resistivity

5. Temperature coefficient of electrical resistance

6. Thermal electromotive force against pure platinum

7. Structure of platinum-rhodium alloys.................... 257

IV. Discussion . . . .

\section{INTRODUCTION}

As part of the study at the Bureau of Standards of the platinumgroup metals of high purity, and to supplement the determination of a number of physical properties of pure rhodium, the preparation and properties of platinum-rhodium alloys were given consideration.

Since rhodium is much less abundant than platinum and the alloys high in rhodium are not easily worked, interest in platinum-rhodium alloys has been limited largely to those containing less than 20 percent of rhodium. Alloys containing about 10 percent of rhodium are used as positive elements in thermocouples, as catalytic gauzes for the oxidation of ammonia to nitric acid, and to some extent as the heating element in resistance furnaces. Alloys containing 3 to 4 percent of rhodium are used for crucibles and similar laboratory ware.

Published information on the physical properties of platinumrhodium alloys is scattered and incomplete. Some of the early work is of doubtful value since reliable methods for the separation, purification, and analysis of the metals of the platinum group were not avail-

\footnotetext{
1 With the cooperation of members of the Bureau staff, as indicated by footnote to several sections of this
} paper. 
able until recently. Some of the more important early investigations were those of Le Chatelier, ${ }^{2}$ Dewar and Fleming, ${ }^{3}{ }^{4}$ Holborn and Wien, ${ }^{5}$ and Barus. ${ }^{6}$ Later, when somewhat better methods for purification had been developed, Burgess, ${ }^{7}$ Sosman, ${ }^{8}$ and Adams ${ }^{9}$ studied the use of platinum-rhodium alloys for measuring high temperatures. Subsequently, Neville ${ }^{10}$ described in detail a method for the preparation of the 10 percent rhodium alloy of high purity for use in thermocouples.

Data on hardness, tensile strength, electrical resistivity, and temperature coefficients of electrical resistance of platinum-rhodium alloys containing $3.5,10,20$, and 50 percent of rhodium were presented by Carter $;^{11}$ Von Wartenberg ${ }^{12}$ determined the melting point of the 10 percent alloy, and Müller ${ }^{13}$ the melting points of a series of platinumrhodium alloys. In the present investigation the "melting point", density, hardness, electrical resistivity, temperature coefficient of electrical resistance, and thermal electromotive force against platinum were determined for a series of alloys which covered the range from pure platinum to pure rhodium.

\section{PREPARATION AND MECHANICAL WORKING}

The alloys were prepared from platinum and rhodium purified in the Chemistry Division of the Bureau by the methods described by Wichers, Gilchrist, and Swanger. ${ }^{14}$ Spectroscopic analysis of the platinum and rhodium showed that the total amount of metallic impurities in each was definitely not over 0.01 percent, probably not over 0.001 percent.

Platinum-rhodium alloys of a nominal rhodium content of 10, 20, $40,50,55,60$, and 80 percent, respectively, were prepared in amounts of 50 to 75 grams by melting in a high-frequency induction furnace. ${ }^{15}$ For all of the alloys, the constituent metals were prepared in the form of pellets made by compressing the spongy metal and sintering the compressed pellets on a block of lime with an oxy-hydrogen torch. The alloys containing 60 percent or less of rhodium were melted in air in zirconium-oxide crucibles and the 80 percent rhodium alloy in vacuo in a thorium-oxide crucible. The alloys containing 10 and 20 percent of rhodium were cast into graphite molds; the others were allowed to freeze in the crucible. All appeared to be homogeneous.

\footnotetext{
${ }^{2}$ H. Le Chatelier, De La Mesure des Temperatures Elévees par les Couples Thermo-Electriques. Jour. de Phys., (2), vol. 6, pp. 23-31, 1887.

3 J. Dewar and J. A. Fleming, On the Electrical Resistance of Pure Metals, Alloys and Non-Metals at the Boiling Point of Oxygen. Phil. Mag., (5), vol. 34, pp. 326-337, 1892.

$4 \mathrm{~J}$. Dewar and J. A. Fleming, The Electrical Resistance of Metals and Alloys at Temperatures Approaching the Absolute Zero. Phil. Mag., (5), vol. 36, pp. 271-299, 1893.

3 I. Holborn and W. Wien, Ueber die Messung hoher Temperaturen. Ann. Physik. vol. 47, pp. 107-134 1892.

6 C. Barus, Thermoelectries of Platinum-Iridium and of Platinum-Rhodium. Phil. Mag., (5), vol. 34,, pp. 376-381, 1892 .

7 G. K. Burgess, On Methods of Obtaining Cooling Curves. B.S. Bull., vol. 5, pp. 199-225, 1908.

${ }^{8}$ R. B. Sosman, The Platinum-Rhodium Thermoelement from $0^{\circ}$ to $1,755^{\circ}$. Am. Jour. Sci., (4), vol. 30 , pp. $1-15,1910$.

p. L. H. Adams, Calibration Tables for Copper-Constantan and Platinum-Rhodium Alloys. Jour. Am. Chem. Soc., vol. 36, pp. 65-72; 1914.

${ }_{10}$ R. P. Neville, The preparation of Platinum and of Platinum-Rhodium Alloy for Thermocouples. Trans. Amer. Electrochem. Soc., vol. 43, pp. 371-384, 1923.

11 F. E. Carter, The Platinum Metals and Their Alloys, A.I.M.E., Proc., Inst. Met. Div., pp. 759-785, 1928.

${ }_{12}$ H. V. Wartenberg, Über optische Temperaturmessung blanker Körper, Verhandl. deut. Physik. Ges.,

vol. 12, pp. 121-127, 1910 . 9-47, 1930 .

14 E. Wichers, R. Gilchrist, and W. H. Swanger, Purification of the Six Platinum Metals. Trans.

A.I.M.E., vol. 76 , pp. $602-630,1928$.

1 The technique of melting, casting, and working these alloys is essentially that described in references 10 and 18.
} 
The ingots were hand forged at $1,100 \mathrm{C}$ (approximate) to bars about $10 \mathrm{~mm}$ in diameter. The alloys containing 40 and 80 percent of rhodium were extremely coarse grained in the initial state, i.e., furnace cooled, and were not forgeable. However, after the ingots had been remelted on lime with an oxy-hydrogen flame, they could be forged. Each of the hot-forged bars was swaged to wire about $1 \mathrm{~mm}$ in diameter. The 10 percent alloy was swaged at room temperature, the others at 900 to $1,000 \mathrm{C}$. The 20 percent alloy could be swaged at room temperature if annealed after each reduction.

Further reduction of the $1 \mathrm{~mm}$ swaged wires was accomplished by drawing through dies. The alloys containing more than 40 percent of rhodium were drawn hot through tungsten carbide dies until the diameter was reduced to $0.5 \mathrm{~mm}$. The temperature of the wire was maintained at about $900 \mathrm{C}$ for the first few draughts, and then gradually lowered for successive draughts to about $550 \mathrm{C}$ for the draught through the $0.5 \mathrm{~mm}$ die. Reduction to $0.2 \mathrm{~mm}$ diameter was accomplished by drawing through sapphire dies, at room temperature and without annealing. The alloys containing less than 40 percent of rhodium were drawn at room temperature from $1 \mathrm{~mm}$ swaged bar to wire of $0.2 \mathrm{~mm}$ diameter.

Determinations of the various physical properties were made during the course of the mechanical working when the form was suitable for specimens for the particular determination desired. Before any determinations were made the specimens were cleaned by immersion in molten potassium bisulphate. This removed surface contamination, especially iron, accumulated during the mechanical working.

The nominal and the actual compositions of the principal alloys, as determined by chemical analysis, ${ }^{16}$ are given in table 1. This series of alloys was used for most of the determinations of properties but alloys similar, although of slightly different compositions, were substituted for the $18.7,37.5$, and 77.1 percent alloys in the determinations of temperature coefficient of resistance, resistivity, and density.

TABLE 1.-Composition of platinum-rhodium alloys

\begin{tabular}{|r|r|r|r|}
\hline \multicolumn{2}{|c|}{ Nominal } & \multicolumn{2}{c|}{ Found by analysis } \\
\cline { 1 - 4 } Rhodium & Platinum & Rhodium & Platinum \\
\hline Percent & Percent & Percent & Percent \\
10 & 90 & 10 & 90 \\
20 & 80 & 18.7 & 81.3 \\
40 & 60 & 37.5 & 62.5 \\
50 & 50 & 51.6 & 48.4 \\
55 & 45 & 56.6 & 43.4 \\
60 & 40 & 61.2 & 38.8 \\
80 & 20 & 77.1 & 22.9 \\
\hline
\end{tabular}

16 The analyses were made by Raleigh Gilchrist, Associate Chemist. Ignition at dull-red heat with sodium chloride in an atmosphere of chlorine was used in getting the alloys, particularly those high in rhodium, into solution. The details of the method of analysis are described in a pending paper. 


\section{PHYSICAL PROPERTIES}

\section{MELTING POINT}

Determinations were made of the approximate "melting point" of each of the alloys containing 10, 18.7, 37.5, 56.6, and 77.1 percent of rhodium. Platinum and rhodium are generally believed to form a continuous series of solid solutions and the melting or freezing in each case occurs over a range of temperature rather than at a single temperature.

The apparatus and procedure were similar to those used in previously reported determinations of the melting points of high-purity platinum and rhodium. ${ }^{17} 18$ An ingot (50 to $75 \mathrm{~g}$ ) of the alloy with a hole drilled axially from top to bottom was placed in a thorium-oxide crucible fitted with a thorium-oxide sight-tube which was inserted

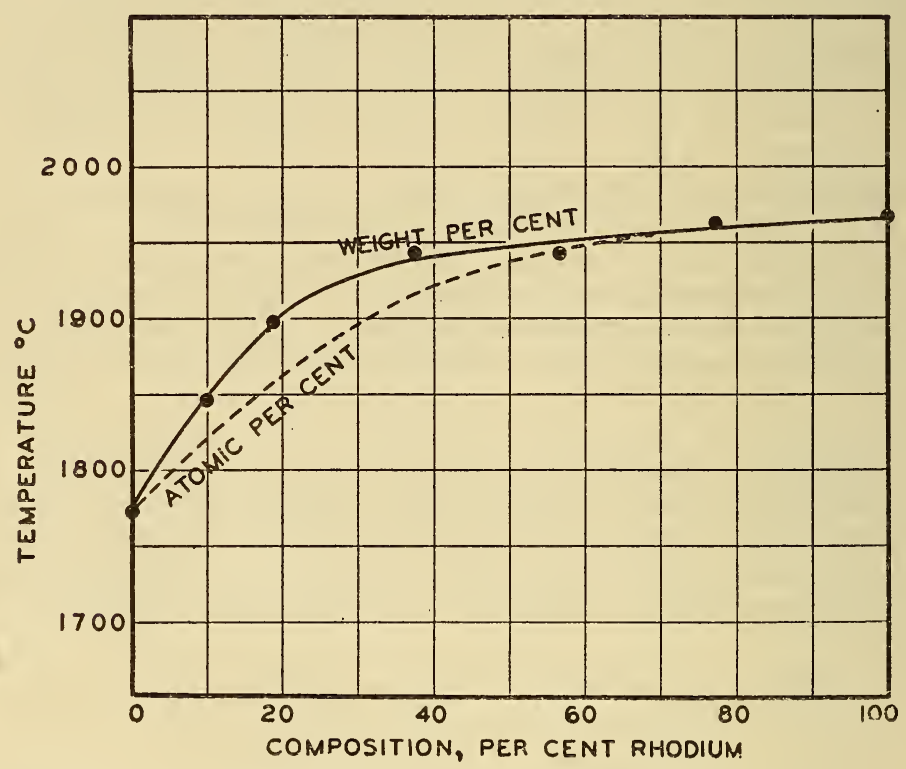

Figure 1.- "Melting Points" of alloys of platinum and rhodium.

in the hole. The power input to the high-frequency induction furnace which was used for melting the ingot was controlled so that several observations of the temperature could be made during melting or freezing. The alloys containing 40 percent or less of rhodium were melted in air; those of higher rhodium content in an evacuated furnace tube, under pressure of less than $1 \mathrm{~mm}$ of mercury.

Temperatures were measured with a Leeds and Northrup optical pyrometer which was calibrated by the pyrometry section of the Bureau before the observations were made and again after they had been completed. The calibration of this pyrometer was certified to $\pm 20 \mathrm{C}$ for temperatures between 1,700 and 2,000 C. Consequently the accuracy of the temperature observations cannot exceed the accuracy, $\pm 20 \mathrm{C}$, of the pyrometer calibration.

17 Wm. F. Roeser, F. R. Caldwell and H. T. Wensel, The Freezing Point of Platinum, B.S. Jour. Research, vol. 6, pp. 1119-1129, 1931.

${ }_{18} \mathrm{Wm}$. H. Swanger, Melting, Mechanical Working and Some Physical Properties of Rhodium, B.S Jour. Research, vol. 3, pp. 1029-1040, 1929. 
In each of the time-temperature curves summarizing the observations during melting and freezing of the different alloys only one break was detected instead of the two that might be expected at the solidus and liquidus temperatures of a solid-solution alloy. In every case, the break was pronounced, and temperatures that were constant, within the uncertainty to which they are given, were obtained both on melting and on freezing over periods of from 2 to 5 minutes. For each of the alloys there was close agreement between the temperatures at which melting and freezing occurred, which indicates that the range between the solidus and liquidus temperatures is probably small. Evidently, at the high temperatures at which the observations were made, the change in the rates of heating or cooling at the solidus and liquidus temperatures was too slight to be detected with the optical pyrometer and the procedure employed.

TABLE 2.- "Melting points" of platinum-rhodium alloys

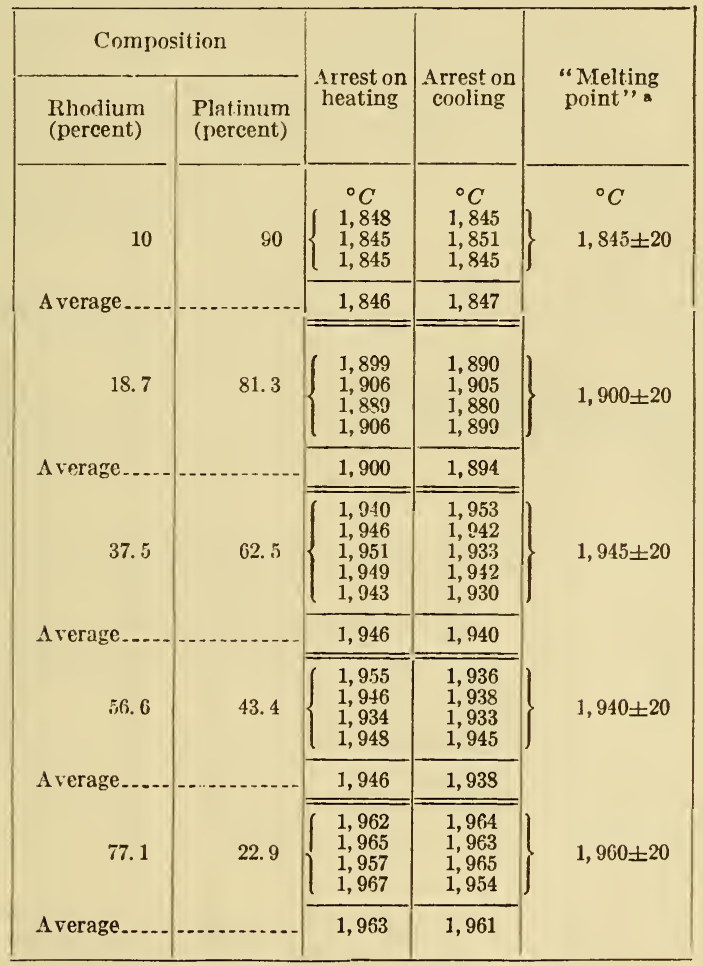

a The limit of accuracy $( \pm 20 \mathrm{C})$ ascribed to each "melting point" is the limit of accuracy of the pyrometer calibration.

From 3 to 5 sets of temperature observations were made during melting and during freezing of each of the alloys. The temperatures during the period in which they remained constant (while melting or freezing occurred) are given in table 2 . The data show that the precision of the experimental results is well within the limits of accuracy of the pyrometer calibration. The average of the arrests during heating and cooling of each alloy, rounded off to the nearest $5 \mathrm{C}$, is designated as the "melting point." Actually this temperature is 
somewhere between the solidus and the liquidus temperatures. In figure 1, the "melting points" are summarized for the various platinum-rhodium alloys, together with the melting (or freezing) points of platinum 1,773.5 $\mathrm{C},{ }^{19}$ and of rhodium, 1,966 C. ${ }^{20}$ The melting

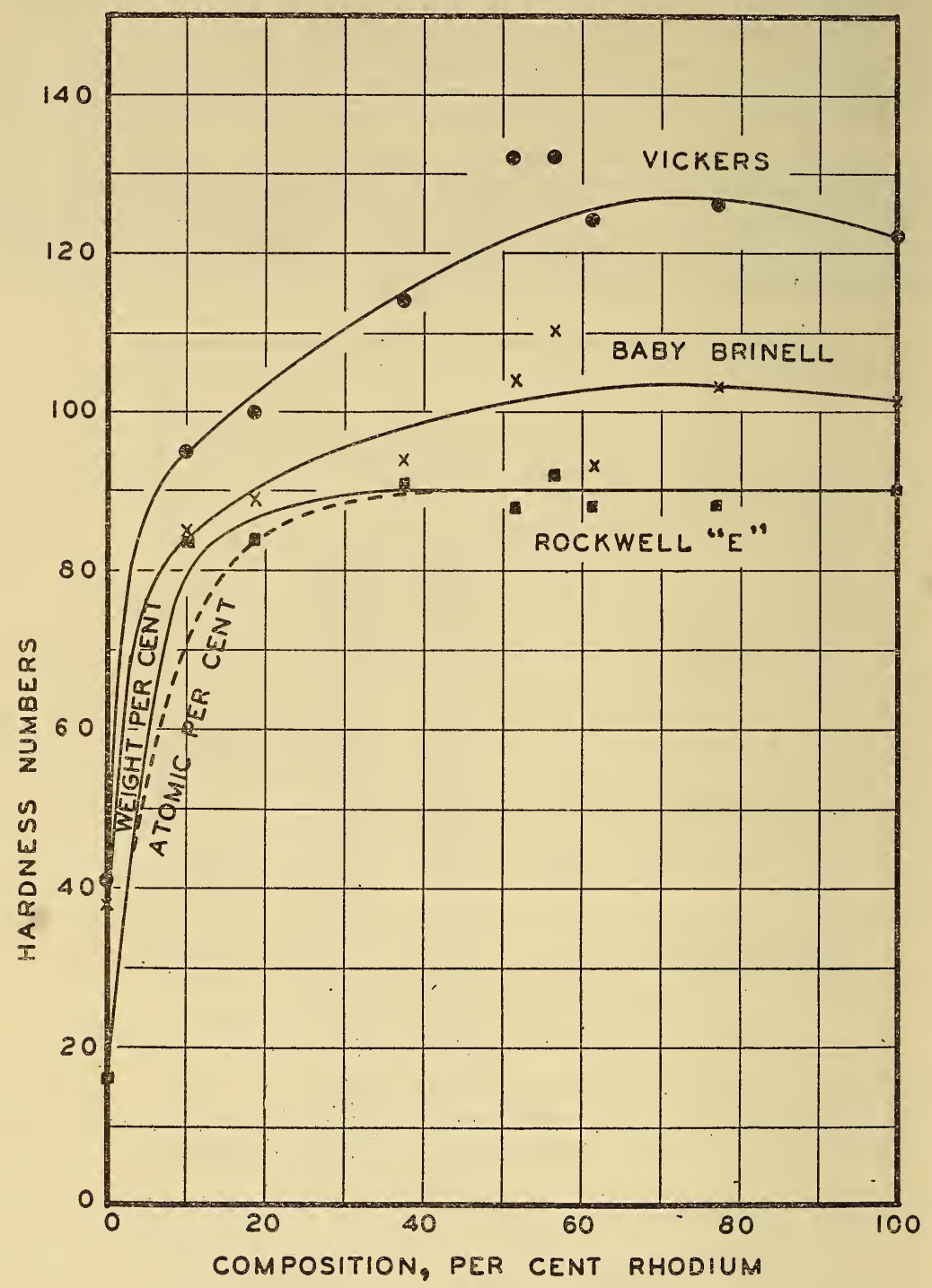

FIGURE 2.-Hardness of platinum-rhodium alloys.

points of all the alloys lie between those of pure platinum and pure rhodium. When plotted on the basis of weight percent, the melting point curve rises sharply from the melting point of pure platinum as the rhodium content is increased to about 40 percent. Further increase in the rhodium content, however, is accompanied by rela-

${ }_{80}$ Determination by W. F. Roeser and H. T. to be Wensel, published subsequently in this journal. 
tively small increases in melting point. If the results are expressed in atomic percent, a smoother curve is obtained and the rapid increase in melting point with additions of rhodium up to 40 percent, is less apparent.

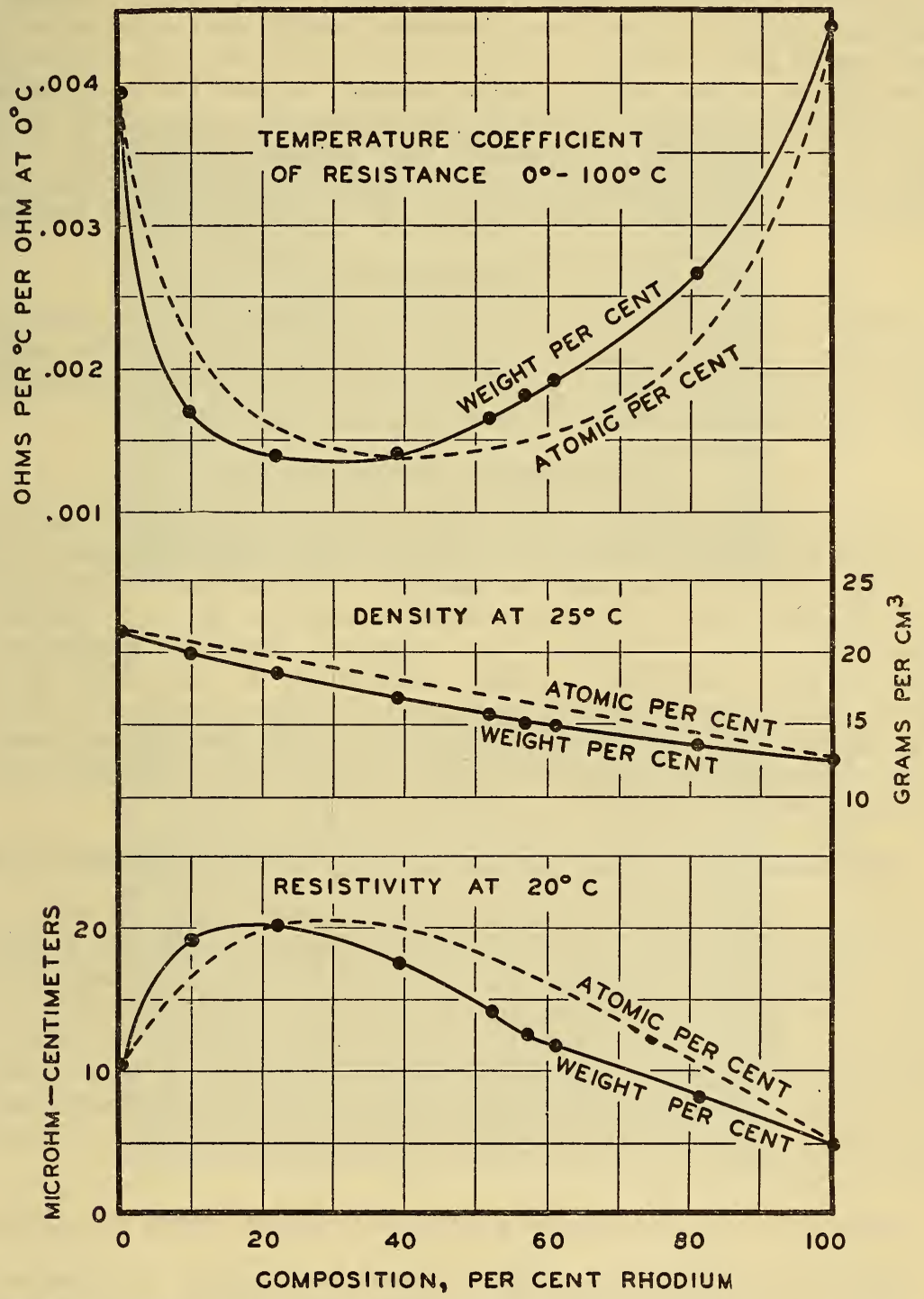

FIGURE 3.-Density, electrical resistivity, and temperature coefficient of resistance of platinum-rhodium alloys.

\section{HARDNESS}

The hardness was determined by means of the Baby Brinell, Rockwell, and Vickers hardness testers. The ingots previously used for the melting point determinations were hot forged to square bars and annealed at 1,200 $\mathrm{C}$ before the hardness impressions were made. 
The results on a weight percent basis are shown graphically in figure 2. The 10 percent rhodium alloy is decidedly harder than pure platinum. With increased rhodium contents above 10 percent the hardness increases at a slower rate, and apparently reaches a maximum at about 70 percent of rhodium. With further increase in rhodium content the hardness decreases slowly, and approaches the hardness of pure rhodium. The Rockwell hardness values have also been plotted on the basis of atomic percent, to show that this method of presentation tends to smooth out the curves particularly in the region of low rhodium contents. The values obtained agree well with the Brinell hardness numbers reported by Carter, ${ }^{21}$ on pure platinum and on alloys containing 10,20, and 50 percent of rhodium.

\section{DENSITY 22}

Density determinations were made on wires $1 \mathrm{~mm}$ in diameter which had been annealed at approximately $1,500 \mathrm{C}$. The values shown in figure 3 indicate that the density of the platinum-rhodium alloys decreases regularly with increasing rhodium content.

\section{ELECTRICAL RESISTIVITY ${ }^{23}$}

The electrical resistivity was measured on wires 1 meter long by $1 \mathrm{~mm}$ in diameter, annealed at a temperature of approximately 1,500 C. The results are plotted in figure 3. The increase in resistivity is fairly rapid with increasing rhodium content up to 20 percent; above 20 percent of rhodium the resistivity decreases gradually to that of pure rhodium. A slight irregularity is noticeable in the curve between 50 and 60 weight percent of rhodium content. Similar relations are apparent when the results are plotted on the basis of atomic percent, but the curve is smoothed out and becomes more symmetrical.

\section{TEMPERATURE COEFFICIENT OF ELECTRICAL RESISTANCE ${ }^{24}$}

The results of the measurements which were made on wires 0.2 $\mathrm{mm}$ in diameter, show (fig. 3 ) that the addition of rhodium to platinum causes a rapid decrease in the coefficients of resistance which reach a minimum value for alloys containing 20 to 40 percent of rhodium; with higher rhodium contents the values again increase regularly and approach the value for pure rhodium. If these results are plotted on the basis of atomic percent, the curve becomes smooth and nearly symmetrical, as would be expected for a series of solid solution alloys.

\section{THERMAL ELECTROMOTIVE FORCE AGAINST PURE PLATINUM}

Some of the alloys prepared for this investigation were included in a series of 10 platinum-rhodium alloys whose thermoelectric properties over the temperature range 100 to $1,200 \mathrm{C}$ have already been published..$^{25}$

\footnotetext{
${ }_{21}^{2}$ See footnote 11, p. 250.

22 E. L. Peffer, Chief, section of capacity and density.

${ }_{23} \mathrm{~A}$. R. Lindberg, junior electrical engineer, section of electrical resistance.

2s F. R. Caldwell, Assistant Physicist, pyrometry section.

${ }_{25}$ Frank R. Caldwell, Thermoclectric Properties of Platinum-Rhodium Alloys. B. S. Jour. Research, vol. 10 , pp. 373-380, 1933.
} 


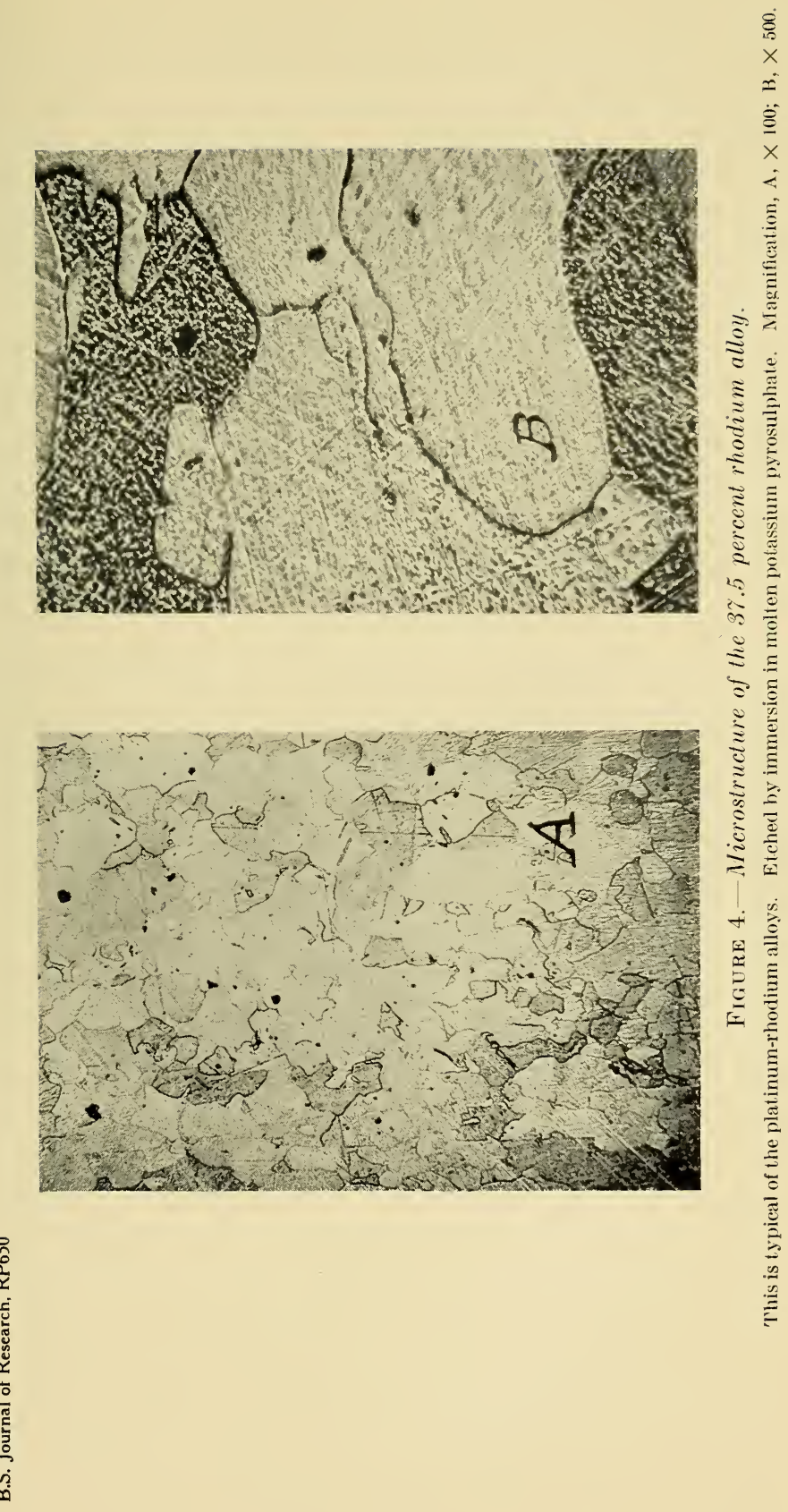




\section{STRUCTURE OF PLATINUM-RHODIUM ALLOYS 26}

Two previous investigators ${ }^{27}$ have stated that platinum and rhodium form a continuous series of solid solutions. In the present investigation, slight irregularities in melting point, Brinell hardness, electrical resistivity, and thermoelectric force of the alloys containing about 55 percent of rhodium suggested the possibility that there might be some departure from a simple solid solution at or near this composition. The presence of impurities, to account for these irregularities, could not be established by chemical and spectrographic analyses.

Examination of the microstructure failed to reveal evidence of any phase except a solid solution in any of the alloys used in this investigation. The specimens used for the microscopic examination were swaged wires, $1 \mathrm{~mm}$ in diameter, which had been annealed at 1,500 C. Figure 4 shows the microstructure of the alloy containing 37.5 percent of rhodium. This was typical of the structure of the other alloys of the series.

$\mathrm{X}$-ray diffraction patterns made from filings of each of the alloys likewise failed to reveal any significant difference in structure to account for the irregularity in properties of some of the alloys. Evidence of the existence of phases other than a simple solid solution was not obtained.

\section{DISCUSSION}

When the technic for the production of rhodium wire was developed ${ }^{28}$ it became possible to use rhodium or platinum-rhodium alloys of high rhodium content for windings on furnaces which were to be operated at temperatures higher than could be reached with platinum. Pure rhodium and an alloy containing 80 percent of rhodium and 20 percent of platinum have been successfully used at this Bureau to maintain furnace temperatures above the melting point of platinum. However, the melting point curve shows that but little advantage can be gained by using alloys containing more than 40 or 50 percent of rhodium. The 40 percent alloy is much easier to work than the 80 percent alloy or pure rhodium and hence should be cheaper, at least at present prices for rhodium and platinum. It also has greater resistivity and a lower temperature coefficient of resistance (both measured at ordinary temperatures) than the alloy of higher rhodium content.

${ }^{26}$ R. E. Pollard and R. G. Kennedy, Jr., Junior Metallurgist and Assistant Metallurgist, respectively. 27 See footnotes 11 and 13, p. 250.

${ }_{33}$ See footnote 18, p. 250 . 
It will be noted that the temperature coefficient of resistance is at a minimum for alloys containing 20 to 40 percent of rhodium and that the resistivity is at its maximum between 10 and 40 percent. In these respects an alloy containing about 20 percent of rhodium is evidently superior to the ordinary platinum winding. Such an alloy can be drawn into wire nearly as easily as platinum and weighs about 15 percent less per unit length. Observations of the 10 and 20 percent alloys in service indicate that they deteriorate less rapidly than platinum, under comparable conditions. For all these reasons they are preferable to platinum for use in furnace windings as long as the cost of rhodium does not rise very much above that of platinum. Only the requirement of a higher operating temperature would appear to justify the use of the less easily worked alloys of higher rhodium content.

Washington, November 10, 1933. 